\title{
Status of Severe Accident Management Guidelines at Kozloduy Nuclear Power Plant
}

\author{
Pavlin Groudev1, Marina Andreeva1, Stilyana Mladenova², Tsvetan Topalov ${ }^{2}$ \\ ${ }^{1}$ Institute for Nuclear Research and Nuclear Energy-Bulgarian Acadeny of Sciences, Sofia, Bulgaria \\ ${ }^{2}$ Kozloduy Nuclear Power Plant, Kozloduy, Bulgaria \\ Email: m_andreeva@inrne.bas.bg
}

Received 2 March 2016; accepted 17 April 2016; published 20 April 2016

Copyright (C) 2016 by authors and Scientific Research Publishing Inc.

This work is licensed under the Creative Commons Attribution International License (CC BY).

http://creativecommons.org/licenses/by/4.0/

(c) (i) Open Access

\section{Abstract}

The objective of this paper is to present the current organization of the Emergency Procedures including Emergency Operating Procedures (EOP) and Severe Accident Management Guidelines (SAMG) in Kozloduy Nuclear Power Plant (KNPP) as a function of the severity of the accident conditions. Special attention is paid to SAMG. It is described when the SAMG are used and at which conditions in a transition between the EOPs and the SAMG should be made. The Critical Safety Function Restoration Guidelines and their connections with SAMGs and EOPs are also discussed. The arrangement of SAMG is described in detail, since in the KNPP exist 2 types of SAMGs for Main Control Room (MCR) and for the Accident Management Centre (AMC) and they contain the same strategies, but they are different in format. Both types are symptom oriented procedures, but those for MCR are in 2-column-format with interconnections, whereas those for the AMC are developed in a logical manner and simplified for people, who take decisions. In the paper, they are also discussed the adopted strategies in existing SAMG that should be followed to recover from a damaged core condition and to prevent or mitigate the release of fission products. In the paper, they are also described a number of technical measures for management and mitigation of severe accidents, which are implemented in KNPP before and after the Fukushima accident. Many of them are common for WWER-1000 type of reactors, but some of them are unique and plant specific. This information can be useful for operators of other WWER type reactors or even PWR reactors.

\section{Keywords}

Nuclear Safety, Emergency Operating Procedures, Severe Accident Management Guidelines

\section{Introduction}

The issues about management and mitigation of severe accidents had been considered after the accidents in

How to cite this paper: Groudev, P., Andreeva, M., Mladenova, S. and Topalov, T. (2016) Status of Severe Accident Management Guidelines at Kozloduy Nuclear Power Plant. Journal of Power and Energy Engineering, 4, 1-8. 
Three Miles Island and Chernobyl, but they received the great attention after the accident in Fukushima in 2011. The readiness of the NPP to react to extreme conditions has been considered and evaluation of constructions, systems and components has been made, the availability and applicability of instructions and procedures as well as the readiness of the personnel to act in extreme conditions. KNPP fulfills number of measures, including installation of new equipment and development of accident procedures, concerning severe accidents. The objective of this paper is to present the current organization of the EOP and SAMG in KNPP as a function of the severity of the accident conditions. EOPs analyses are designed to provide the response of monitored plant parameters to identify symptoms available to the operators, timing of the loss of critical safety functions and timing of operator actions to avoid the loss of critical safety functions or core damage. The general philosophy of EOP analyses is described in detail in [1]. During the development of SB EOPs at KNPP, a number of thermal-hydraulic analyses for KNPP have been performed at the Institute for Nuclear Research and Nuclear Energy-Bulgarian Academy of Sciences (INRNE-BAS) using RELAP5/MOD3.2 computer code [2]-[6]. Several studies related to the accident management strategy are described in [7] [8]. SAMG are required when an accident situation is not handled properly through the use of EOP thus leading to a partial or a total core melt [9] [10]. IAEA requirements related to safety and operating organizations for NPP are mainly contained in the [11]-[15]. Safety requirements for accident management in Bulgaria are contained in the [16]-[18].

\section{SAMG Development}

The use of the SAMG is required when an accident situation is not handled properly through the use of EOP thus leading to a partial or a total core melt. The source of radioactive products likely to be released into the environment increases as the fission products are released from the fuel elements. Since radioactive releases can potentially be extremely large, the utmost priority is the assurance of confining radioactive products. This is the reason why the entrance in the SAMG leads to a switch of operating priorities: in the EOPs the priority is to save the fuel, in the SAMG the priority is to save the containment. The purpose of the SAMG is to define beforehand specific action to perform on order to: avoid or limit radioactive release; avoid or delay the possible loss of containment integrity in order to give more time to activate the Emergency Plan for public protection; bring the unit back to a controllable state; keeping the corium under water inside the pressure vessel is a key objective in order to regain control of the situation.

The severe accident management strategies include:

- Primary pressure reduction;

- Primary circuit coolant supply;

- Steam generators pressure reduction;

- Steam generators feed water supply;

- Containment conditions management.

These main strategies are included in the Severe Accident Management Guidelines. They should be fulfilled simultaneously when the technical conditions for their realization are available.

For each of the strategies the following steps are defined:

- The appropriate systems and equipment for fulfillment of the relevant strategy are defined;

- The measurement channels, which are available to control the Core and the Containment, are defined;

- The positive and the negative consequences of applying each one of the strategies are evaluated.

\section{Management Concept during Normal and Accident Conditions}

The arrangement of the procedures in KNPP in dependence of the deviation of normal or accidental conditions is shown in Table 1.

\section{SAMG Types}

\subsection{SAMG for Main Control Room (MCR)}

The SAMG for MCR are used by the operating personnel. They are symptom based step-by-step procedures, which are used in MCR in case of a severe accident. The main view of the procedures is the same as those in EOP and it is shown in Figure 1. They are logical trees in which defined parameters are checked and decision is taken. 
Table 1. Arrangement of procedures in KNPP.

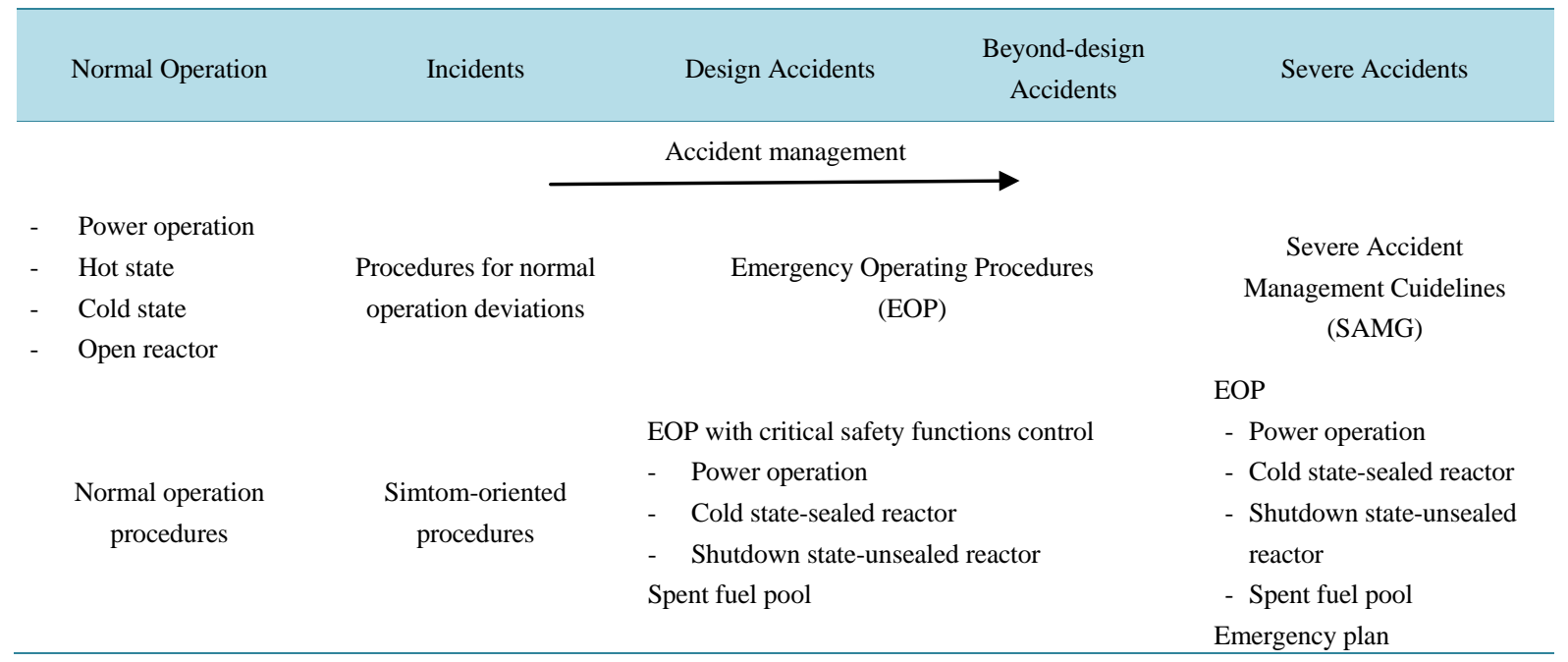

SAMG-01

INITIAL ACTIONS AT A SEVERE ACCIDENT

\begin{tabular}{|c|c|c|}
\hline Step & ACTIONS/EXPECTED RESULT & UNRECEIVED RESULT \\
\hline \multicolumn{1}{|c|}{$\begin{array}{l}\text { NOTE } \\
\text { Make introduction of the boron dilution in to the reactor core by every } \\
\text { possible way }\end{array}$} \\
\hline
\end{tabular}

Decreasing of the pressure in the core

a. Check the pressure in the core

IF the pressure is below $25 \mathrm{kgf} / \mathrm{cm}^{2}$, -OVER $186 \mathrm{kgf} / \mathrm{cm}^{2}$ THEN switch on pump 6TQ2 to the primary circuit

IF you succeed to switch on pump TQ2 to the primary circuit, THEN GO TO step 3

IF the pressure is below $110 \mathrm{kgf} / \mathrm{cm}^{2}$, THEN switch on pump 6TQ3 to the primary circuit

IF you succeed to switch on pump TQ3 to the primary circuit, THEN GO TO step 2

b. Start poening of YP21S01 by impulse opening of YP2 1 S09

b. Open all available valves:

b1. Maintain YP21S08

$$
\text { -OPENED. }
$$

- YR61S01•YR62S01・YR63S01

- YR51S01•YR52S01•YR53S01

- YR01S01•YR02S01•YR03S01

c. Monitor the pressure in the core -DECREASES

c. Open all available valves:

- YR61S01•YR62S01•YR63S01

- YR51S01•YR52S01•YR53S01

- YR01S01•YR02S01•YR03S01

d. Check the temperature at the assemblies' exit

d. IF the temperature at the core exit grow up to $980^{\circ} \mathrm{C}$, THEN GO TO SAMG - 02 "Long lasting actions at -DECREASES 
The implementation of the procedures starts when there are indications for core degradation. These procedures describe specific operators' actions (main and alternative). They are divided on:

- SAMG 00-Loss of $6 \mathrm{kV}$ power supply-total blackout;

- SAMG 01-Immediate actions;

- SAMG 02-Long term actions.

SAMG for shutdown state, open reactor and SAMG for spent fuel storage tank are developed as well.

The transition between EOP and SAMG is necessary when critical safety functions are violated and there is no possibility for recovery.

\subsection{SAMG for Accident Management Center (AMC)}

The SAMG for AMC have different shape in comparison with the SAMG for MCR and the example is shown in Figure 2. Their structure consists of logical schemes, graphs and appendixes. The structure is the same as SAMG for MCR and the same strategies are used. It is considered, that their shape is more appropriate for people who are responsible for taking decisions and managing the accident.

\section{Important Equipment for Severe Management}

\subsection{Containment Hydrogen Reducing System}

According the design 8 passive autocatalytic recombiners (PARs) are installed. They are capable, based on fully passive principle, to recombine hydrogen and oxygen into water steam. According to the performed analyses they are sufficient for recombining the hydrogen, which will be generated during in-vessel phase of the severe accident. In 2013/2014 are installed 15 additional PARs per unit, and the origin of these PARs is from 3 and 4 unit of KNPP. With these additional PARs they are sufficient for recombining the hydrogen, generated during outside vessel phase of severe accident. Scheme of PARs are shown in Figure 3.

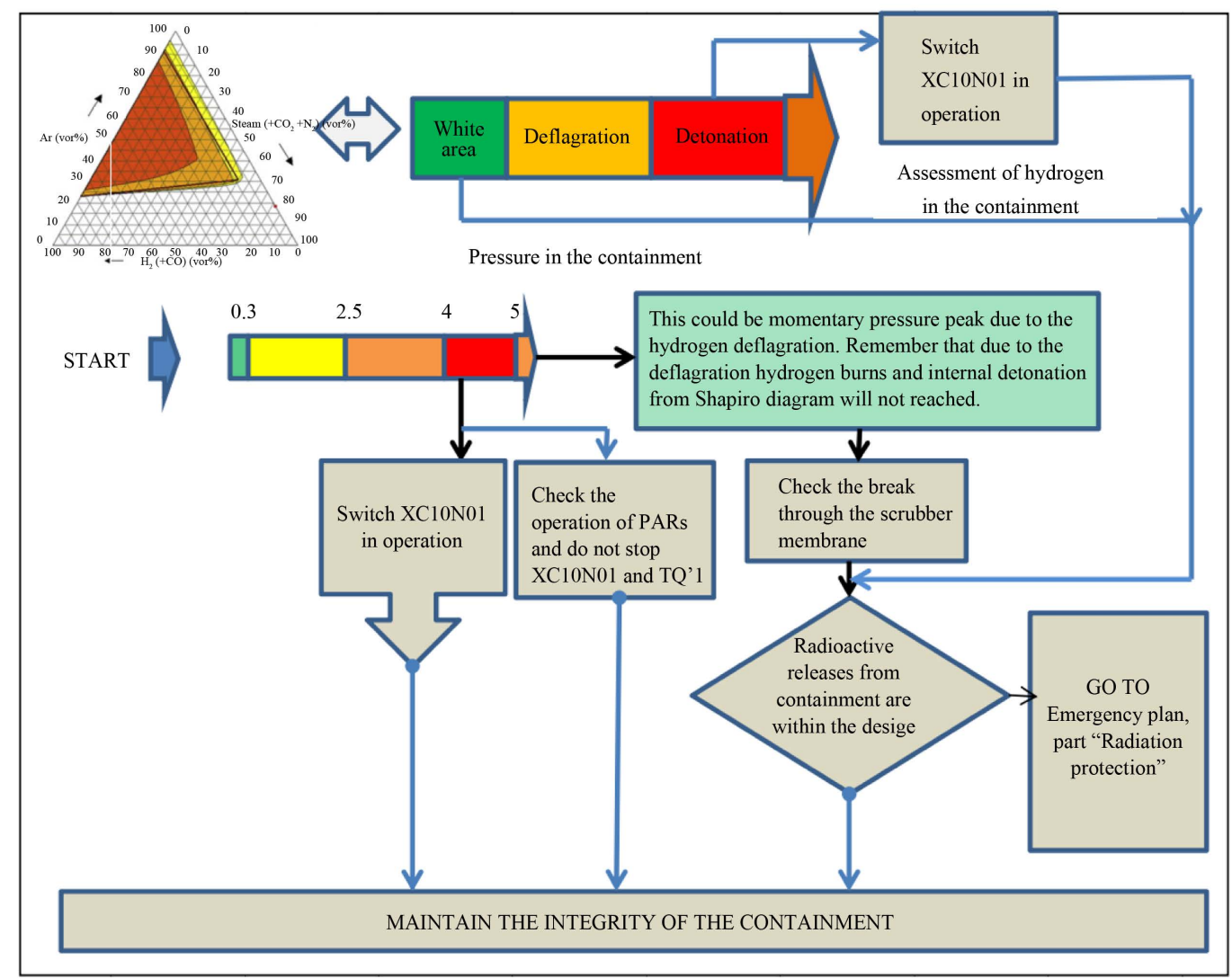

Figure 2. The view of shape of SAMG for AMC. 


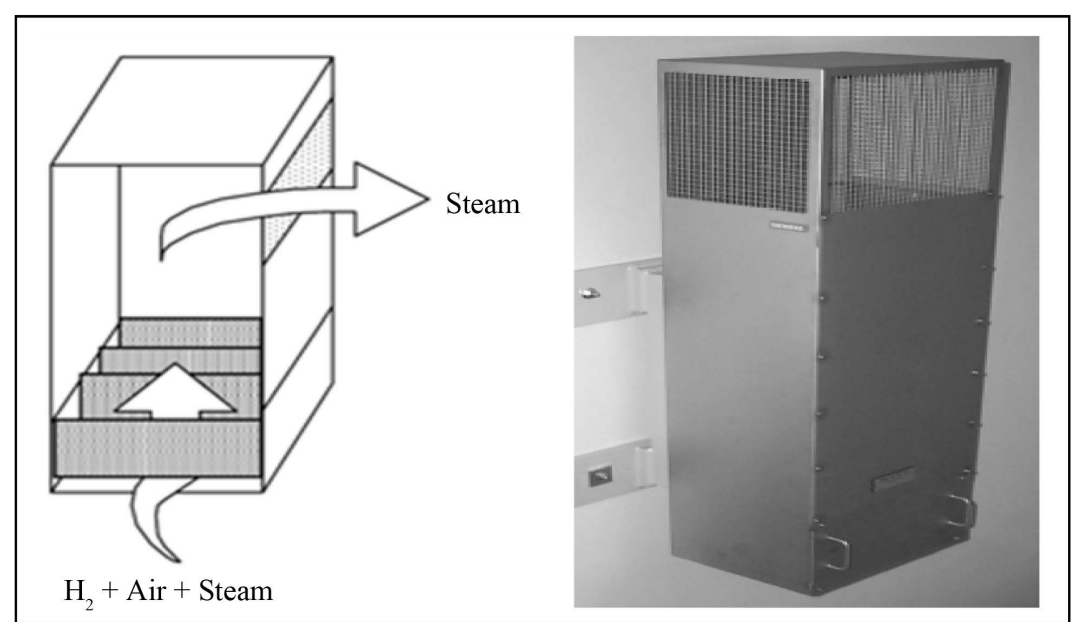

Figure 3. Passive autocatalytic recombiners.

\subsection{After Accident Containment Pressure Reducing System}

The main performance of this system (Figure 4) is as follow:

- Prevent overpressure in the containment beyond set pressure;

- The valves could be operated outside the containment;

It is equipped with membrane that ruptures when pressure exceeds $0.49 \mathrm{MPa}$.

\subsection{Alternative Steam Generators Feed Water}

A new pump is installed which uses the available lines for emergency feed water. It uses the 3 tanks, $500 \mathrm{~m}^{3}$ each, filled with purified water. It has independent power supply by mobile diesel generator.

\subsection{Detectors for Steam under Reactor Vessel Cap}

The detectors measure the core outlet temperature. Their range is up to $1200^{\circ} \mathrm{C}$. They measure the water level in the reactor vessel.

\subsection{Wide Range Thermo-Couples}

They are situated on the reactor vessel (lower cylindrical part) and they measure the temperature in the area, where critical heat flux is expected. Their range is between $500^{\circ} \mathrm{C}$ and $1300^{\circ} \mathrm{C}$. The layout of wide range thermos-couples in reactor vessel is presented in Figure 5.

\subsection{Post-Accident Monitoring System (PAMS)}

It has three independent measurement channels and triple power supply. It measures:

- Reactor water level;

- Core outlet temperature;

- Departure from boiling over the core and in the hot legs;

- Steam generator levels;

- Pressure in the containment-up to 10 bars;

- Pressurizer level;

- Hot and cold legs temperatures;

- Activity in the containment;

- Aerosols in the containment;

- Neutron power of the reactor;

- Levels in the emergency tanks;

- Safety systems flows. 

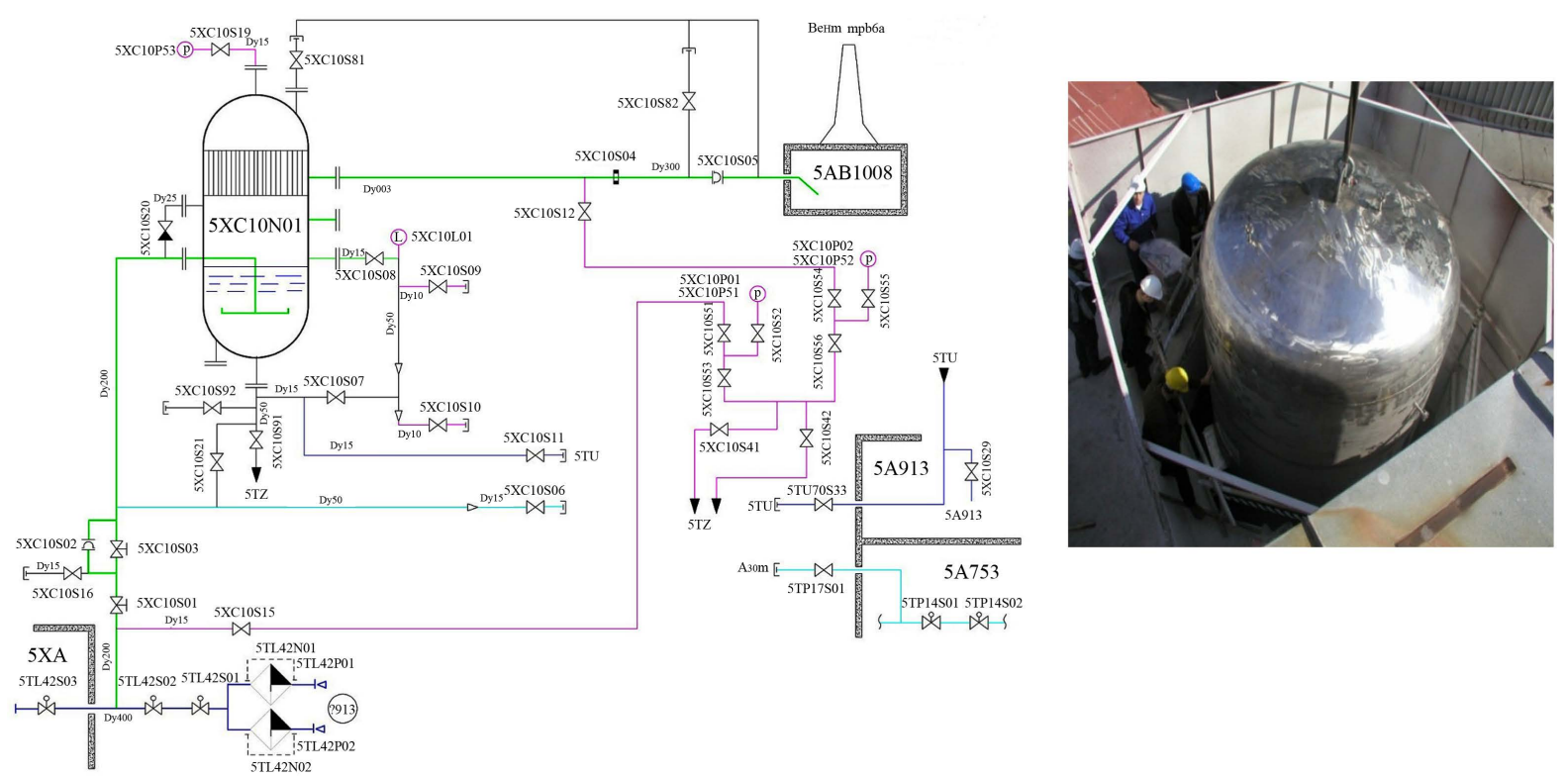

Figure 4. The containment pressure reducing system.

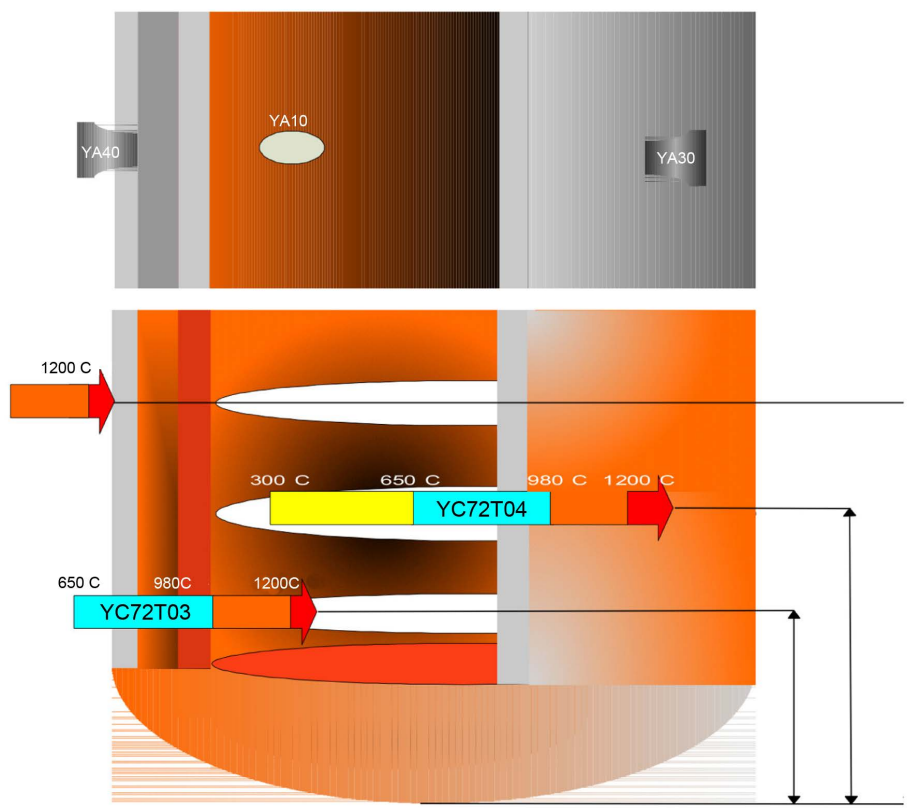

Figure 5. The layout of thermos-couples in reactor vessel.

\subsection{Safety Parameter Display System (SPDS)}

It is installed not only in MCR of units 5 and 6, but also in emergency control rooms, in accident management centre and in Nuclear Regulatory Agency in Sofia.

\subsection{Electrical Power Supply}

In NPP Kozloduy, there are 3 independent levels of connections with national electrical system and neighbor countries-11 transit lines on $400 \mathrm{kV}, 220 \mathrm{kV}$ and $110 \mathrm{kV}$. In 1999 two new additional transformers were installed BT 07 and BT 08 for providing the second additional supply for the two units.

According to the design there are 3 diesel generators (DG) per each unit, and during the modernization one 
additional non-mobile DG per unit is installed with capacity 5.4 MW. These generators could be connected to the electric buses normal operation and it could also supply some of the electric buses for safety systems in case of safety system DG failure.

Additionally after the Fukushima accident 2 mobile diesel generators (one per each unit) are installed. They are $0.4 \mathrm{kV}$ and they could supply with power the pump for alternative steam generators feedwater. KNPP has also available one mobile DG $6 \mathrm{kV}$ common for the two units, which could be used for charging the safety systems accumulators in case of a total blackout.

Each unit is equipped with 3 accumulator batteries for safety systems and 3 accumulator batteries for normal operation systems. According to an experiment conducted in KNPP the safety system accumulators could provide supply for more than 10 hours without charging.

\subsection{High Temperatures Safety Devices}

For resolving the problem with early bypass of the containment new high temperature safety devices (plugs) are installed. They could withstand temperatures over $2000^{\circ} \mathrm{C}$. According to the performed analyses they delay the penetration through the concrete with more than 2 hours. They are produced from melting resistant ceramic materials and installed into the ionizing chambers channels and into the horizontal openings of the reactor shaft. The cavity of VVER-1000 type reactor is presented in Figure 6.

\subsection{Water Supply for the Spent Fuel Pools}

New pipelines are designed and installed, which could supply water from mobile fire engine to spent fuel pools in case of total loss of all options for supplying water from design sources.

\subsection{New Center for Accident Management}

The project for building a new center is ongoing. It will be situated outside the NPP site in the town Kozloduy.

\section{Conclusion}

In the last years, a great attention was made to the possibilities of the nuclear power plants to manage severe accidents. In KNPP, a number of measures are implemented including feed water supply, electric supply and providing measuring channels, which are capable of operation in severe accident conditions. Many procedures and working instructions for severe conditions are developed. Of course, safety improvement and finding the possibilities for mitigation and management of severe accidents are continuous process and they shall continue forward.

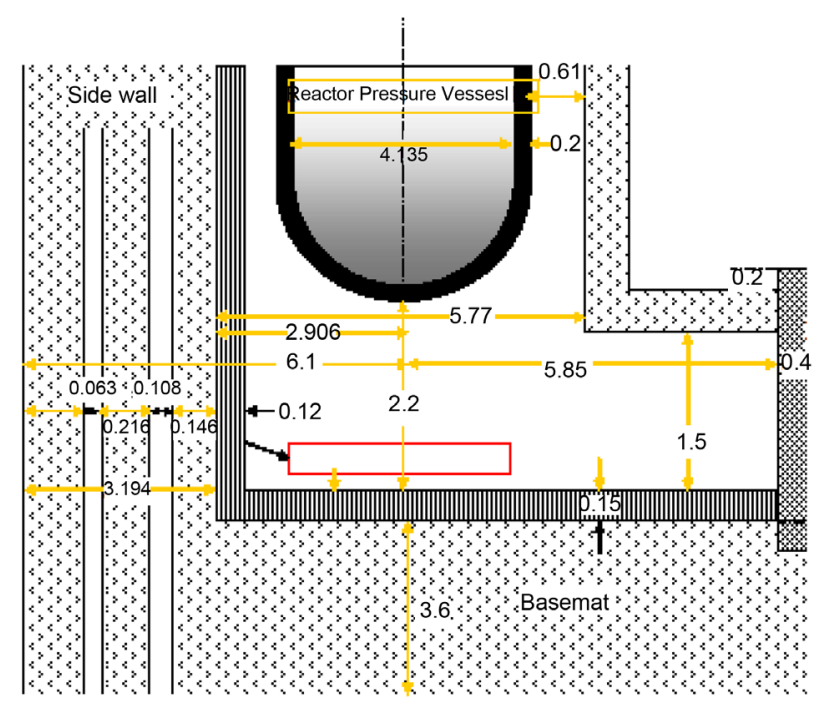

Figure 6. Cavity of VVER-1000/V320 reactor. 


\section{Acknowledgements}

The authors acknowledge to the EC supported CESAM Collaborative Project (Grant Agreement No 323264) for funding of our research.

\section{References}

[1] Pavlova, M.P., Groudev, P.P. and Hadjiev, V. (2007) Systematic Approach for the Analytical Validation of Kozloduy NPP, VVER-1000/V320 Symptom Based Emergency Operating Procedures. Progress in Nuclear Energy, 50, $27-32$. http://dx.doi.org/10.1016/j.pnucene.2007.10.002

[2] Pavlova, M.P., Andreeva, M. and Groudev, P.P. (2007) RELAP5/MOD3.2 Blackout Investigation for Validation of EOPs for KNPP VVER-1000/V320. Progress in Nuclear Energy, 49, 409-427. http://dx.doi.org/10.1016/j.pnucene.2007.06.001

[3] Andreeva, M., Pavlova, M.P. and Groudev, P.P. (2012) Investigation of Critical Safety Function "Heat Sink” at Low Power and Cold Condition for Kozloduy Nuclear Power Plant WWER-1000/V320. Annals of Nuclear Energy, 40, 221228. http://dx.doi.org/10.1016/j.anucene.2011.10.012

[4] Groudev, P., Andreeva, M. and Pavlova, M. (2013) Investigation of Nuclear Power Plant Behaviour at Low Power and Cold Conditions during an Overpressurization in Primary Circuit. Annals of Nuclear Energy, 62, 231-241. http://dx.doi.org/10.1016/j.anucene.2013.06.026

[5] Pavlova, M.P., Andreeva, M. and Groudev, P.P. (2015) Steam Line Break investigation at Full Power Reactor for VVER-1000/V320. Nuclear Engineering and Design, 285, 65-75. http://dx.doi.org/10.1016/j.nucengdes.2015.01.006

[6] Kadreva, M.A. and Groudev, P.P. (2015) Study of Bounding Cases for Primary to Secondary Leakage for VVER1000/V320. Comptes Rendus de L'Academie Bulgare des Sciences, 68, 1365-1372.

[7] Tusheva, P., Schäfer, F. and Kliem, S. (2012) Investigations on Optimization of Accident Management Measures Following a Station Blackout Accident in a VVER-1000 Pressurized Water Reactor. ICAPP, 1, 11-24.

[8] Tusheva, P., Schaefer, F., Reinke, N. and Weiss, F.P. (2010) Assessment of Early-Phase Accident Management Strategies in a Station Blackout Scenario for VVER-1000 Reactors. 18th International Conference on Nuclear Engineering, Xi'an, 17-21 May 2010, 921-932. http://dx.doi.org/10.1115/ICONE18-29954

[9] Andreeva, M., Pavlova, M.P. and Groudev, P.P. (2008) Overview of Plant Specific Severe Accident Management Strategies for Kozloduy Nuclear Power Plant, WWER-1000/320. Annals of Nuclear Energy, 35, 555-564. http://dx.doi.org/10.1016/j.anucene.2007.08.005

[10] Borisov, E., Grigorov, D. and Mancheva, K. (2013) Study of Long-Term Loss of All AC Power Supply Sources for VVER-1000/V320 in Connection with Application of New Engineering Safety Features for SAMG. Annals of Nuclear Energy, 59, 204-210.

[11] IAEA (2012) Safety of Nuclear Power Plants: Design, Specific Safety Requirements 2.1, Revision of NS-R-1.

[12] IAEA (2001) The Operating Organization for Nuclear Power Plants, Safety Guide, No. NS-G-2.4.

[13] IAEA (2000) Operational Limits and Conditions and Operating Procedures for Nuclear Power Plants, Safety Guide, NS-G-2.2.

[14] IAEA (2009) Severe Accident Management Programmes for Nuclear Power Plants, Safety Guide, No. NS-G-2.15.

[15] IAEA(2006) Safety Report Series 32, Implementation of Accident Management Programmes in NPPs.

[16] BNRA - Bulgarian Nuclear Regulatory Agency (2004) Statute Book on the Safe Use of Nuclear Energy. Vol. 1, Sofia.

[17] KNPP. Set of SEVERE Accident Management Guidelines-RUTA0,0, RUTABOK, RUTABMP, KNPP.

[18] КNРР.Б.АГ.ПЛ.001/04 Emergency Plan of NPP “Kozloduy”. 